\title{
O IMAGINÁRIO E A IMAGEM DO MAL NO ANTI-HERÓI EZIO NO JOGO DIGITAL ASSASSIN'S CREED II
}

Mônica Lima de Faria

Universidade Federal de Pelotas

monicalfaria@gmail.com

Resumo: Este artigo objetiva uma análise e reflexão do personagem antiherói Ezio no jogo digital Assassin's Creed I/ produzida pela Ubisoft. Através da contemplação de sua expressão gráfica utilizando a Hermenêutica de Profundidade de Thompson, observa-se a construção do imaginário do personagem anti-herói e suas representações de bem e mal. A análise é realizada em três etapas, sendo elas: apresentação do personagem - que contextualiza o anti-herói de maneira introdutória -; imaginário e moral do mal - que discute o protagonista analisado em relação às noções de imaginário e mal -; e imaginário e imagem do mal - quando são abordadas as relações das manifestações visuais através da expressão gráfica do personagem e a construção de seu imaginário como dubiedade entre bem e mal.

Palavras-chave: imaginário, imagem, mal, Ezio, expressão gráfica

\begin{abstract}
This article aims an analysis and reflection of the anti-hero character Ezio in the digital game Assassin's Creed I/ produced by Ubisoft. Through contemplation of their graphic expression using of Thompson's Hermeneutics in Depth, there is the imaginary construction of the antihero character and their good and evil representations. The analysis is performed in three steps, namely: presentation of the character - that contextualizes the anti-hero in an introductory way -; imaginary and moral of evil - discussing the protagonist analyzed in relation to imaginary notions and evil -; and imaginary and image of evil - when addresses the relationship of visual manifestations through the graphical expression and character building of its imaginary as ambiguity between good and evil.
\end{abstract}

Keywords: imaginary, image, evil, Ezio, graphic expression 


\section{INTRODUÇÃO - APRESENTANDO O PERSONAGEM}

Através do jogo digital Assassin's Creed II (Ubisoft, 2009), este trabalho analisa o imaginário do mal do anti-herói Ezio Auditore, pensando na sua moralidade, em suas imagens e representação gráfica. Ezio Auditore é o protagonista de três dos vários títulos da série de games Assassin's Creed - Assassins's Creed II (2009) (Figura 01); Assassins's Creed II - Brotherhood (2010); e Assassins's Creed II - Revelations (2011) -, desenvolvida pela Ubisoft Montreal. Neste trabalho, será levado em conta o título Assassin's Creed II (2009) para delimitar o objeto de análise.

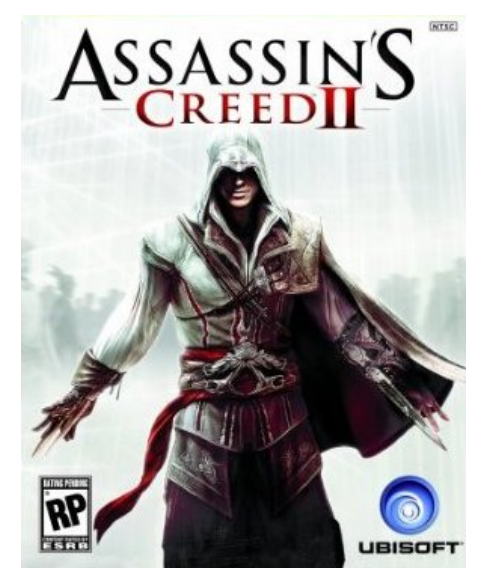

Figura 01 - Assassin's Creed II

Fonte: http://assassinscreed.ubi.com/revelations/en-GB/home/, em 04/04/2012

A análise é realizada em três etapas, sendo elas: apresentação do personagem - que contextualiza o objeto -; imaginário e moral do mal - que discute o ant-herói analisado em relação aos referenciais teóricos sobre o imaginário e o mal -; e imaginário e imagem do mal - quando são abordadas as relações das manifestações visuais do personagen e a construção de seu imaginário como representação do mal.

Todo imaginário é um desafio, uma narrativa inacabada, um processo, uma teia, um hipertexto, uma construção coletiva, anônima e sem intenção. $O$ imaginário é um rio cujas águas passam muitas vezes no mesmo, lugar, sempre iguais e sempre diferentes (SILVA, 2006 p.8).

O imaginário pode ser então uma construção, permeada de vivências, sensibilidades, repertórios etc. Diferente do que o termo popularmente sugere, o imaginário não é oposto ao real, mas sim uma projeção ou introjeção (SILVA, 2006) do real, uma relação entre consciente e inconsciente gerando uma manifestação de compreensão mútua entre aqueles que o compartilham. $O$ imaginário é real enquanto imaginário.

Assim sendo, criar heróis e tecer assim laços, faz parte das atividades do imaginário sensível. Segundo Luyten:

Os homens têm uma necessidade interna de heróis. Eles são campeões do bem, restauradores da ordem e praticamente 
imutáveis no tempo e no espaço. Povoam um setor privilegiado do nosso imaginário, governado pela fantasia (LUYTEN, 2000, p.69).

Sendo assim, o herói é a figura da passagem sobre as adversidades, sendo vitorioso ou não, é uma representação de superação e que comunica algo, uma mensagem de conotações diversas dependendo de suas várias facetas de acordo com o meio. Já o vilão pode ser entendido como a própria adversidade, o ato falho, quem dará o teste ao herói. O vilão perverso, maligno, ambicioso torna-se necessário para que o herói possa ser herói. O personagem anti-herói, centro deste estudo, é entendido também como um herói, porém, ao contrário das expectativas que temos para com este, traz consigo uma maldade, inerente ao vilão (FARIA, 2013).

Deve-se compreender que a figura do anti-herói aqui tratada é de um personagem. Já na Grécia antiga, refletindo sobre o teatro, Aristóteles referia-se ao personagem como a imitação de algo, ideias ou pessoas reais: "Como os imitadores imitam pessoas em ação, e estas são de boa ou má índole (porque os caracteres se limitam a esses), sucede que, necessariamente, os poetas imitam homens melhores ou piores, ou então iguais a nós" (ARISTÓTELES, Poética. Trad. Baby Abrão, 2000, p.38). Para o filósofo, o personagem não seria somente uma simples representatividade do ser humano, mas à sua importância na elaboração e todo o desenrolar da obra a partir das ações por ela desempenhadas.

O personagem vilão, por sua vez, é então um personagem que, como outros, trata-se de um tipo de imitação de algo real. A diferença deste personagem é que está calcado em valores imorais ou amorais em relação à éticaapresentada pelo herói: o vilão é a representação do mal. De acordo com Ullmann (2005), o mal é considerado uma propriedade dos seres, porém uma propriedade não-positiva, falha; ainda segundo o autor, o mal também pode ser carnal, físico ou doloroso de espírito. Seguindo estas ideias, pode-se afirmar que a função do personagem vilão é a de uma criatura má, falha, que não condiz com o bem moral e que por isso é capaz de infringir o mal físico ou o de espírito.

Isso quer dizer que o mal, em qualquer sentido, consiste na ausência de uma perfeição que deveria estar presente na natureza, em determinado ser ou faculdade de um ser. Em outras palavras, o mal é aquilo que contraria um plano determinado ou desarruma uma ordem estabelecida de coisas que estamos habituados. Assim sendo, o mal é oposto de bem (ULLMANN, 2005, p.6).

Seguindo esta ideia, pode-se entender que o mal é uma privação do bem, portanto o bem, necessário para existência do mal, não é passível de negação, de privação, não pode ser rejeitado, fascina o homem. No bem não existe o mal. Todavia, pensamento contém um equívoco em relação ao personagem vilão como representação do mal e do personagem herói enquanto representação do bem: o herói do bem, para assim ser, deve ter sido infligido por algum mal, seja físico ou de espírito; pois só assim, conhecendo o mal e o tendo experenciado é que será possível enfrentá-lo como um herói (CAMPBELL, 2007). O anti-herói assim surge: sofrido e vingativo pelo mal sofrido. 
Ullmann (2005) ainda afirma que existem três tipos de mal: o mal físico, o mal moral e o mal metafísico. O mal físico é aquele que deforma de alguma maneira a boa naturalidade do homem, seja ela material ou de espírito. O mal físico pode ser ou uma conseqüência da natureza ou da violência, sendo ela física ou psicológica. Já o mal moral "reside no desvio voluntário da norma de moralidade, que é a razão, nas ações livremente postas" (ULLMANN, 2005, p. 9); é o desvio do ser da conduta moral e ética preestabelecida. Por fim o mal metafísico é aquele que reside em uma "imperfeição original da criatura, que a torna sujeita ao erro, à falta, ao pecado" (ULLMANN, 2005, p.9), é um mal de certa maneira "natural", não explicável, imponderável, inerente ao ser maléfico; pode-se dizer que muitas vezes este é o caso do vilão de ficção

Eco (2007), em História da Feiúra, afirma que a representação do mal na imagem, na arte e na comunicação visual trata-se muitas vezes da representação do feio, do imperfeito, o contrário do belo. O mal, enquanto visualização é então aquilo que não está dentro das regras do que é belo, do que é bom.

Para explicar o mal no mundo, já desde tempos remotos, existe a doutrina do dualismo: um espírito ou princípio do bem e outro princípio ou espírito do mal (...). Ao homem sábio cumpre escolher o espírito do bem, seguir-lhe os pensamentos e as ações para ser feliz. Terrível futuro espera os que se pautarem pelo espírito do mal (...). Os dois espíritos acham-se em luta perene, a qual só terminara ao fim dos tempos com a vitória do bem e a aniquilação do mal (ULLMANN, 2005, p.12-13).

Apesar do senso comum de dualidade bem e mal ao qual Ullmann (2005) se refere, essas noções só podem ser atribuídas a visão de mundo ocidentalizada, baseada em paradigmas morais medievais e modernos. Estes paradigmas, baseados em uma doutrina judaico-cristã, entendem o mal como uma conseqüência, surgida historicamente pelo pecado original (ULLMANN, 2005). O anti-héroi surge como um exemplo de representação de em uma condição pós-moderna na qual vivemos contemporaneamente, os parâmetros de bem e mal se tornam relativos e com fronteiras culturais, geográficas, sociais e contextuais.

\section{DESENVOLVIMENTO}

\subsection{Apresentação do personagem}

O protagonista do jogo é um jovem nobre carismático e encrenqueiro, filho de um rico banqueiro da Florença renascentista. A história começa quando o pai e os irmãos de Ezio são mortos devido a uma conspiração política, da qual o rapaz consegue escapar juntamente com sua irmã caçula e a mãe perturbada após a morte da família. Ao fugir de Florença jurando vingança aos carrascos de seu pai, Ezio recorre ao auxílio de um tio, que explica os motivos da conspiração. Através de Mario - o tio o rapaz se descobre envolvido em uma trama maior, que revela uma guerra velada entre duas facções: a da Ordem dos Assassinos e a dos Templários. Sendo por herança um membro da Ordem dos Assassinos, Ezio começa seu treinamento a fim de vingar a 
morte de seu pai contra Rodrigo Borgia - mais tarde o Papa Alexandre $\mathrm{VI}$ - grande conspirador do assassinato ${ }^{1}$.

Ezio então abraça a causa da Ordem dos Assassinos que, historicamente, coloca-se em posição reacionária às tiranias ou regimes totalitários vigentes, defendendo uma ideia "libertária" contra as dominâncias políticas, sociais etc. Ainda assim, mesmo concordando e agindo de acordo com os ideais dos Assassinos, Ezio é motivado não pelo bem maior defendido pela Ordem, mas pelo seu desejo pessoal de vingança pela morte de sua família.

Na franquia de jogos Assassin's Creed, a Ordem dos Assassinos é associada às rebeliões populares e outras manifestações de contestação contra o governo ou abuso de poder de minorias privilegiadas ao longo da história da humanidade. A Igreja, através da Ordem Templária, é o principal alvo dos Assassinos na obra de ficção devido ao poderio político expansionista ordenador associado à corrupção, então os Assassinos não deixam de ter um cunho anarquista, criticando o poderio ordenado e defendendo a "liberdade" de a humanidade seguir seu caminho. Ao longo da análise se falará mais a respeito de Ezio e da história de Assassin's Creed II.

\subsection{Imaginário e moral do mal em Ezio}

Entende-se Ezio como um anti-herói primeiramente por sua motivação: vingança. $O$ personagem antes de ter as ações conduzidas para um bem maior - 0 ato heróico, conforme Campbell (2007) - ele busca saciar o seu sentimento de falta, punir aqueles que o fizeram mal. Segundo Maffesoli (2004, p 124):

[...] o espírito de vingança - como a "vendetta", no caso extremo pode ser entendido como uma experiência dessa "religação", uma forma de solidariedade, de participação na comunidade. Alguma coisa foi perturbada na ordem social, é preciso concertar. A vingança como "ato reparador e salvador" é algo que pode parecer paradoxal, mas, sem justificar seus aspectos criminais, é preciso reconhecer sua dimensão ética. Ela cimentou um corpo social.

Observando a afirmação de Maffesoli (2004), entende-se que a vingança é um "mal justificado", o que se encaixa no caso de Ezio. Em nenhum momento se julga o ato do protagonista como criminoso, mas sim como um "acerto de contas" legitimado, apesar de sorrateiro e discordante de um código ético que verificaria uma ordem legal de "não matar". Ezio rompe com a ordem moral, se utiliza de técnicas obscuras - de assassinato -, torna-se então um criminoso, inflige o mal moral e físico, mas, ainda assim, é considerado um herói, pois suas ações são consideradas punidoras, conforme Ricoeur (2007) de um mal maior. O imaginário da vingança gera uma violência justificada - no caso do jogo - conferindo ao personagem um poder de julgar e condenar, segundo Ricoeur (2007).

Este aspecto vingativo do herói, ou anti-herói - acaba gerando outra condição: a de um personagem humanizado. Diferentemente dos heróis clássicos de honra

\footnotetext{
1 Informações disponíveis em http://assassinscreed.wikia.com/wiki/Ezio_Auditore_da_Firenze, acesso em 20/03/2012.
} 
inabalável e que a tudo venciam, conforme Cappelari (2007), o Assassino é frágil uma vez que se abala com a violência sofrida e cede ao seu impulso maligno de querer causar o mal aos seus malfeitores, indo de acordo com o pensamento de Nietzsche (2010) ao se religar a uma animalidade, um impulso visceral e naturalmente humano de sobrevivência e reação. Assim, o personagem humanizado, ou seja, com ações que refletem o comportamento humano, causando uma ligação ou projeção-identificação, segundo Morin, In Xavier (2003) do, personagem com o jogador, "o individuo é causa e efeito da lógica da identidade", de acordo com Maffesoli (2004, p. 95). De acordo com Legros, Monneyron, Renard e Tacussel (2007, p. 119):

A importância do personagem heróico na eficácia simbólica da narração fantástica é evidente. A imagem imaginária fragiliza a angústia dá lugar à criação recíproca de uma imagem imaginária que afronta essa primeira imagem. Este combate e dá em torno de uma angústia predominante (ás vezes, várias), e a função fantástica tem, como principal objetivo, a regulação desta.

Ressaltando que Ezio é personagem de um jogo digital, mais do que a ligação imaginária de o herói fazer o bem social para o social - mesmo que por motivações pessoais -, tem a ligação maior de o jogador "ser" o personagem. Essa ligação de identificação é potencializada pelo meio, dando ao usuário a potencia de ser, de julgar, de condenar o mal.

Ezio é um anti-herói também porque mata, como o próprio nome da ordem sugere, ele é um assassino. O imaginário ou noção de "assassino" é notoriamente ligado ao mal, afinal assassino é aquele que gera a morte. Sendo assim Ezio é um pecador, carrega o pecado da morte, pratica o mal, mas, é considerado bom. Uma dubiedade e postura oriundas de um contexto pós-moderno, que permite a ambivalência da moralidade do herói, como afirma Rahde (1997).

A violência causada pelo Assassino é então justificada por uma outra moralidade, a da punição dos maiores vilões, aqueles que, além de terem feito o mal para o personagem, conspiram para um mal maior que afeta todo o contexto social e moral de dominação. $O$ bem pessoal que veio antes do bem maior é desculpado, pois a violência da punição é aceita, e os efeitos conseqüentes do ato de vingança geram o bem maior. Conforme Maffesoli (2004, p. 73-74):

O retorno cíclico da violência alimenta-se do vazio em que se transformou o instituído. É a partir que ela pretende refundar outra coisa. É isto o querer-viver. Inconsciente de si mesmo, nem por isso deixa de ser criador. Ele é uma "força que vai", cujo aspecto construtivo só pode impor-se depois de realizada a obra de sua ação destrutiva.

Seguindo as ideias de Ricoeur (2007), a violência, o mal físico gerado por Ezio são então fases necessárias para atingir bem, seja a felicidade, ou preenchimento do vazio do personagem, seja acabar com um esquema que visa algo que - no jogo - é considerado maléfico para todo um espectro social. A Ordem dos Assasssinos, ao condenar o controle ordenador templário reagindo a ele com atos violentos, sugere 
uma "ética da revolução", através do motim, da guerrilha e da revolta dos grupos, fazendo valer - de certa maneira - o caos como predecessor do bem.

A morte não é o único mal cometido por Ezio. O personagem ao longo do game rouba lugares e pessoas, sendo uma das formas de se conseguir dinheiro no jogo. Essa atitude não é justificada na história, ao mesmo tempo não é condenada, sendo sim um desvio de conduta ética do herói. Outra característica é que o personagem se relaciona e tem entre seus contatos pessoas e facções do submundo como as guildas de ladrões, mercenários e prostitutas. Pessoas dessas facções são, inclusive, os maiores contatos e aliados do Assassino, tendo ajuda e lutando pelas mesmas causas que pessoas que são consideradas criminosas ou marginais. Estas relações mostram uma subversão dos valores heroicos apresentados no jogo, ao mesmo tempo vão ao encontro do espírito reacionário e de contestação ao dar voz e importância às minorias sociais.

Ainda assim, Ezio cumpre com a jornada do herói, uma vez que, mesmo inicialmente relutante, aceita seu destino e enfrenta os antagonistas. Porem Ezio também apresenta uma mudança drástica em reação às posturas éticas e virtuosas esperadas de um herói, suas atitudes levam que ele seja simultaneamente herói e bandido, em um equilíbrio sinérgico entre bem e mal que representa o imaginário da condição pós-moderna.

\subsection{Imaginário da imagem do mal em Ezio}

No jogo Assassin's Creed II o protagonista Ezio (Figura 02) em sua representação gráfica contem algumas características dos heróis: é bem constituído, carismático e charmoso. Porém, ao mesmo tempo, o Assassino apresenta algumas outras características que são não usuais nos heróis: é brigão, mulherengo, não tem escrúpulos em roubar e matar, e apresenta uma cicatriz no rosto - sendo esta uma marca deste e de outros protagonistas da franquia Assassin's Creed. Então, pode-se observar de início que a imagem de Ezio não é perfeita, tendo, apesar do charme e ser "bem apessoado", algo de feio, relativo ao mal, de acordo com as ideias de Eco (2007).

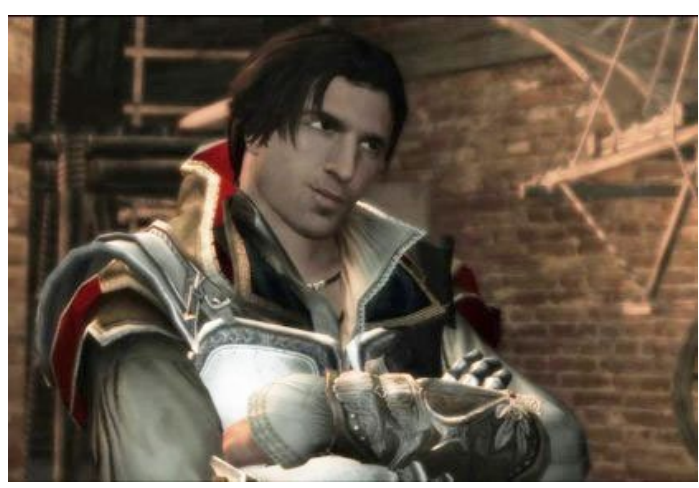

Figura 02 - Ezio sem capuz

Fonte: http://thisheapofthings.blogspot.com.br/2010/11/assassins-creed-ii-my-reason-to-avenge.html, em 04/04/2012

$\mathrm{Na}$ própria história do jogo, o personagem começa com uma postura de "playboy", promovendo confusões ao dormir com mulheres e/ou arranjar brigas de rua de maneira indisciplinada. A postura do personagem vai amadurecendo ao longo 
do jogo, o que faz juz à ideia de herói e sua jornada, tornando-se menos impulsivo ou promovendo menos o caos por diversão, e assumindo melhor as conseqüências de seus atos, mesmo que, por muitas vezes ainda apresente características do seu antigo comportamento, como com brigas e mulheres.

O já comentado fato de que o personagem se relacionar com prostitutas, ladrões e mercenários também colaboram na construção da imagem do anti-herói. Ao fazer contato com estes indivíduos Ezio aparece, nas cenas do jogo, escondendo-se e localizando locais furtivos e obscuros, assim como as cenas de diálogo apresentam certa tensão, com os personagens falando baixo, como se alguém pudesse estar vendo ou escutando de maneira secreta. As representações gráficas dos personagens do submundo apresentam também algumas peculiaridades, sendo muitas vezes figuras "feias" com postura agressiva, corroborando com o imaginário deste nicho.

Já Ezio é representado de forma diferenciada uma vez que apresenta certas contradições. O Assassino veste roupas brancas - cor que representa a Ordem dos Assassinos - extremamente ornamentadas - além da estética da Itália Renascentista, onde se passa o jogo -, com capuz, capa e carregando muitas armas. Os trajes brancos e ricos em detalhes conotam uma certa riqueza condizente com o status de nascença do personagem mas não com o discurso libertário da Ordem (Figura 03). Provavelmente, o excesso de adornos das vestimentas e armadura venham a desempenhar o papel de identificação do herói como tal, uma vez que a imagem tem este papel, e sua construção polissêmica acaba por ser um reflexo das manifestações visuais pós-modernas, como afirmam Rahde e Cauduro (2005).

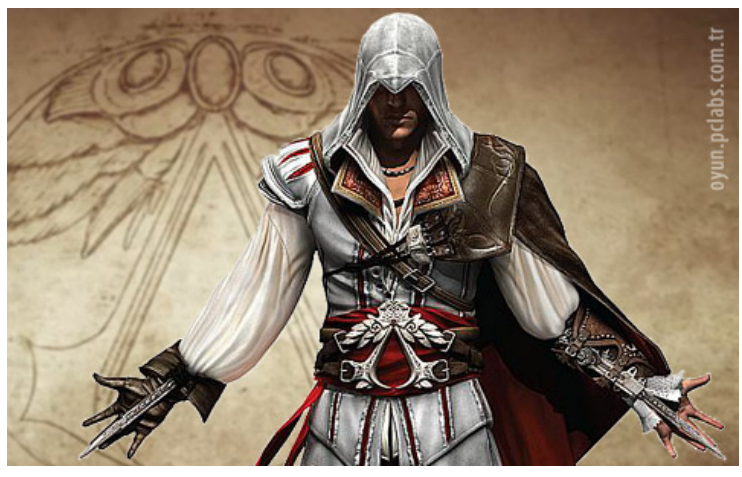

Figura 03 - vestes ricas em detalhes e excessos

Fonte: http://www.techzilla.it/assassins-creed-revelations-due-nuovi-fantastici-video-hd-2931/, em 04/04/2012

O fato de o personagem utilizar sempre capuz e máscara também confere a ele um caráter misterioso e sinistro. O ocultar-se, ficar à sombra gera a sensação de medo, desconhecimento e mistério. De acordo com Ruiz (2003) a imagem é essencial para atribuir sentido ao imaginário que não é concreto, "por esse motivo, quando produz o sentido das coisas, tem que objetivar o ideal num objeto concreto". Assim, ao construir a visualidade de Ezio, existe a preocupação o caráter misterioso e místico, uma vez que o herói é dúbio e dado a ações malignas apesar das boas intenções. "A transformação das impressões em imagens com sentido é a obra-prima do imaginário", como afirma Ruiz (2003). Essa a potencialidade criadora do imaginário da qual fala o autor. Segundo Legros, Monneyron, Renard e Tacussel (2007, p. 119): 
A morte está por toda aparte na sociedade humana; ela é inexplicável se permanece indizível e, por conseqüência, duplamente destrutiva. É por esse motivo que ela sonha figuras particulares, para que ela seja uma vez mortal, figuras que nos dão um pouco de certeza (ou, mais exatamente, previsibilidade): saber por quais razões a morte nos escapa é dar os meios de conhecimento do tempo da finitude, do "quando" se arrisca a ultrapassar.

Ezio por ser um assassino acaba por representar a morte - mais um motivo para ser considerado um anti-herói ao invés de um herói -, ele gera a morte. Sua figura misteriosa e enigmática, ligada ao sonho e pesadelo é a primeira representação disso, outras são seus artefatos: as armas. Ao longo do jogo, o personagem porta diversos armamentos diferentes, assim como são demonstradas inúmeras técnicas, para os seus assassinatos que estão disponíveis para a escolha do jogador (Figura 04). A relação da arma com a morte se dá através do ato de violência, da dor e do sofrimento causado, e menos com o simbolismo da arma do herói, como instrumento de justiça. Isso porque, tanto as armas como as inventivas técnicas de assassinato em Assassin's Creed não carregam nenhum elemento místico, mas sim são objetos com os quais se gera a morte.

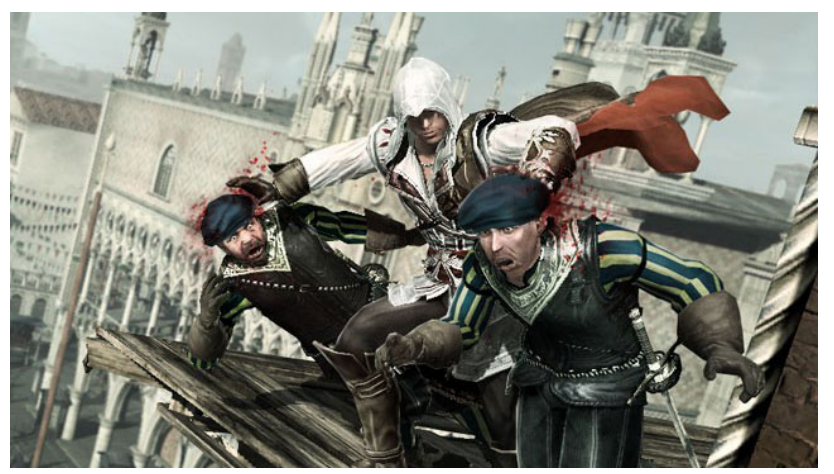

Figura 04 - cenas de assassinatos

Fonte: http://assassinscreed.ubi.com/revelations/en-GB/home/, em 04/04/2012

Existe, porém, no jogo, artefatos místicos que perpassam todos os títulos. 0 mais relevante em Assassin's Creed II é a Maçã do Éden, com um poder de destruição imenso e que é justamente o alvo de desejo dos Templários na narrativa. A Maçã se apresenta como um objeto místico e poderoso sendo então procurada ao longo do jogo pelos Assassinos para guardá-la e pelos Templários para usá-la como instrumento de dominação. $O$ artefato representa então o desejo de poder e a conduta moral em relação a ele: usá-lo para o bem ou para o mal, justificando então o lado heroico do protagonista.

Ao se passar na Itália da Renascença, na história do jogo Ezio encontra alguns personagens que realmente existiram, esse artifício é típico das narrativas pósmodernas que adicionam dados reais à ficção, conferindo um caráter imaginário fictício e fantástico ao game. Dentre esses personagens estão ilustres como o mecena e estadista Lorenzo di Medici - que torna-se um benfeitor do protagonista e simpático à causa dos Assassinos -, e Leonardo da Vinci (Figura 05) - que, inclusive, é quem projeta as complexas armas utilizadas por Ezio. A utilização de personagens históricos na obra de ficção certamente auxiliam na construção de verossimilhança do imaginário 
do jogo, o que faz com que a narrativa torne-se, ainda que fictícia, mais crível. As representações visuais gráficas dos cenários das cidades italianas na época da Renascença também passam por essa construção, aparecendo no jogo locais famosos de cidades como Florença (Figura 06) e Veneza. Conforme Maffesoli (2004, p. 119120):

Ser herói é ser reconhecido como tal, é porque está sintonizado com as características comuns. Ele participa do húmus coletivo. Mais que produtor, ele é o "produto" de sua época, em relação de amor com ela. É próprio de uma relação como esta ser ambígua. Disto o princípio de contradição, que devemos entender em sua acepção lógica, vem a ser uma expressão privilegiada. A oscilação entre o bem e o mal, o escuro e o claro, o céu e a terra, acentua, em sua dinâmica própria, aquilo que caracteriza o que é vivo. As qualidades morais do santo, do herói, do gênio são, claro, importantes, mas seus defeitos não o são menos. É com as duas coisas que o homem sem qualidades comungará.

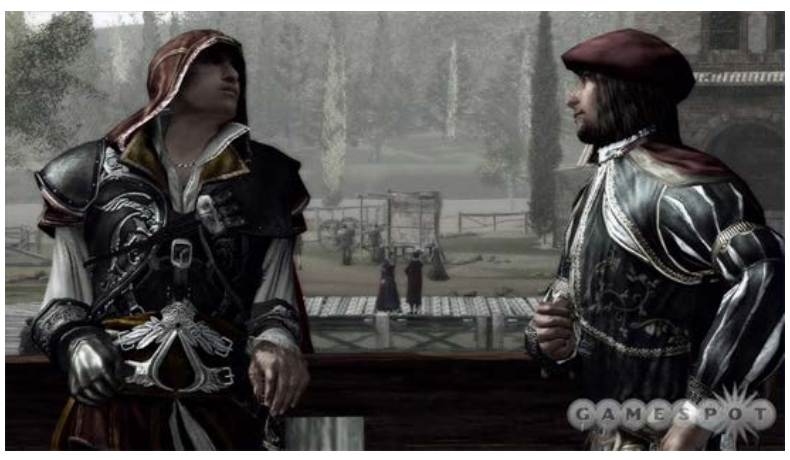

Figura 05-Ezio e Leonardo da Vinci

Fonte: http://diadegamer.nerdrops.com/2010/game-on-assassins-creed-2/, em 04/04/2012

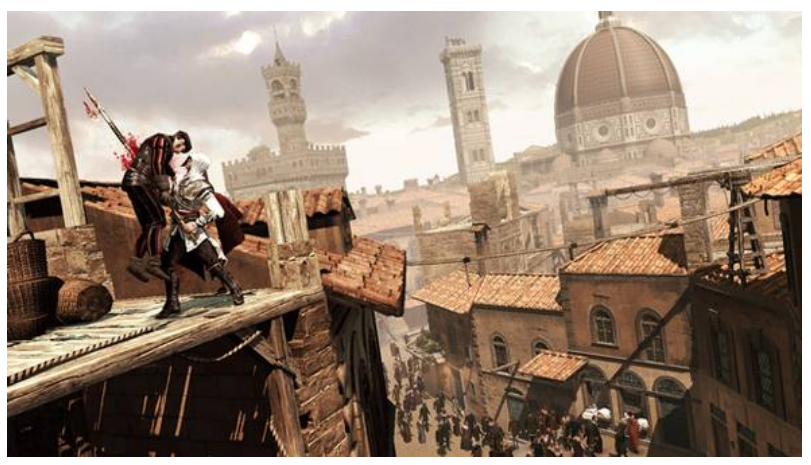

Figura 07 - Florença no jogo

Fonte: hhttp://assassinscreed.ubi.com/revelations/en-GB/home/, em 04/04/2012

Ezio é ambíguo, dúbio, polissêmico, ele representa ao mesmo tempo o bem, é o herói, o salvador e benfeitor, e o mal, a morte, a violência; ele causa a dor, julga e pune, comete crimes, mas estes são entendidos como justificados. Essas características são então comuns aos heróis pós-modernos, ou, assim chamados antiheróis. Interessante essa condição que permite um herói autoproclamado assassino. Essas contradições apresentadas em Ezio confirmam uma mudança no entendimento 
moral e ético de bem e mal que são vislumbrados na pós-modernidade. Para o bem ou para o mal, os heróis mudaram.

\section{CONCLUSÃO}

Ezio não é um vilão, porém nem todas as suas atitudes e visualidades o encaixam no estereótipo do herói, isso o faz um anti-herói pós-moderno exatamente pelas incertezas de suas ações seus benefícios como herói, ao mesmo tempo carregadas da certeza enquanto as suas justificativas. Ezio motiva-se pela vingança, preencher o vazio deixado pela violência sofrida, assim causando mais violência. 0 personagem representa então o mal da violência e do julgamento, o assassinato como a justa causa de punição a um mal já realizado. O que não deixa de ser um poder e soberba, pois se é juiz e carrasco do pecado de outro. $O$ anti-herói é calcado em um imaginário moral da revolução, a violência justificada, a luta contra um mal maior para fins benéficos, o mal de Ezio tem um propósito, considerado benéfico.

Ezio, por fim, carrega consigo características visuais em sua representação gráfica tanto do herói quanto da representação da violência, criando uma ambivalência que fazem dele um anti-herói, um personagem polissêmico que ora pode ser visto como bom, ora como mal.

Ao observarmos os gráficos da construção visual do jogo Assassin's Creed II, especificamente no que se refere ao anti-herói Ezio, podemos afirmar a importância da expressão gráfica como construtora e consolidadora de imaginários e poéticas visuais contemporâneas.

\section{REFERÊNCIAS}

ARISTÓTELES. Poética. In: Os Pensadores - Aristóteles. São Paulo: Nova Cultural, 2000. Ética a Nicômaco. Bauru: Edipro, 2009.

CAMPBELL, Joseph. O herói de mil faces. São Paulo: Pensamento, 2007.

CAPPELLARI. Márcia S. V. As representações visuais do mal na comunicação: imaginário moderno e pós-moderno em imagens de A Divina Comédia e do filme Constantine. Porto Alegre: PUCRS, 2007.Tese (Doutorado em Comunicação), Faculdade de Comunicação Social, Pontofícia Universidade Católica do Rio Grande do Sul, 2007.

ECO, Umberto. História da feiúra. Rio de Janeiro: Record, 2007.

FARIA, Mônica. Imagem e Imaginário dos vilões contemporâneos. Pelotas: Editora e Gráfica Universitária UFPEL, 2013.

LEGROS, Patrick, MONNEYRON, Frédéric, RENARD, Jean-Bruno \& TACUSSEL, Patrick. Sociologia do imaginário. Porto Alegre: Sulina, 2007.

LUYTEN, Sonia M.Bibe. Mangá - O Poder dos Quadrinhos Japoneses. São Paulo: Hedra, 2000. 
MAFFESOLI, Michel. A parte do diabo - resumo da subversão pós-moderna. Rio de Janeiro: Record, 2004.

MORIN, Edgar. A Alma do Cinema. In XAVIER, Ismail (org.). A experiência do cinema. São Paulo: Graal, 2003.p.145 - 172.

NIETZCSHE, Friedrich. A Genealogia da moral. São Paulo: Companhia das Letras, 2010.

RAHDE, Maria Beatriz. Os Universos de Raymond e Druillet: releitura de imagens e reflexões pedagógicas. Porto Alegre: PUCRS, 1997. Tese (Doutorado em Educação), Faculdade de Educação, Pontifícia Universidade Católica do Rio Grande do Sul, 1997.

RAHDE, Maria Beatriz, CAUDURO, Flávio Vinícius. Algumas características das Imagens Contemporâneas. In: XIV ENCONTRO ANUAL COMPÓS. Niterói: UFF, 2005.

RICOEUR, Paul. Evil - a challenge to philosophy and theology. New York: Continuum, 2007.

RUIZ, Castor Bartolomé. Os paradoxos do imaginário. São Leopoldo: Editora Unisinos, UBISOFT MONTREAL. Assassins Creed II. Ubisoft, 2009.

ULLMANN, Reinholdo. O mal. Porto Alegre: EDIPUCRS, 2005. 